\title{
Pasión de hospitalidad, pasión hospitalaria: relación encubierta
}

\section{Passion of Hospitality, Hospitable Passion: \\ Conceals Relationship}

\author{
Alberto MOREIRAS \\ Texas A\&M University \\ moreiras@tamu.edu
}

\section{Resumen}

Mi comentario al ensayo de Davide Tarizzo publicado en este volumen busca leerlo contra el trasfondo de la posibilidad de una suspensión infinita de la soberanía. Tarizzo no llega a considerar esto último en su propuesta, sino que prefiere suspender la suspensión misma por mor de lo que llama realismo político. Aunque todo realismo político es apreciable, siempre queda expuesto a la posibilidad de ocultamiento teórico. Mi argumento es que el ensayo de Tarizzo esconde una radicalidad denegada que cancela la posibilidad teleológica histórico-política a favor de una conflagración democrática posthegemónica. Presento la propuesta de Tarizzo como una inversión aparente de los pensamientos de Heidegger en la posguerra mundial sobre el habitamiento europeo.

Palabras clave: hospitalidad, Europa, Unión Europea, soberanía, Heidegger, filosofía de la historia.

\begin{abstract}
This is a commentary on Davide Tarizzo's essay published in this volume that tries to read it against the background of the possibility of the infinite suspension of sovereignty. Tarizzo stops short of suspending sovereignty, in his proposal for a future of the European Union, in order to suspend its very question for the sake of political realism. While political realism is commendable, it leaves itself open to the possibility of theoretical concealment. My contention is that Tarizzo's essay hides a disavowed radicality that cancels out the possibility of political-historical teleology in favor of a posthegemonic democratic conflagration. I present Tarizzo's proposal as a sort of inversion of Heidegger's post-WWII thoughts on European inhabitation.

Keywords: hospitality, Europe, European Union, sovereignty, Heidegger, philosophy of history.
\end{abstract}


Entre el alcance espacio-temporal que se mueve hacia la dominación planetaria y el movimiento de asiento que es funcional a tal dominación por un lado, y el deseo de los humanos de habitar en su sitio en el viaje y la localidad, por otro, prevalece posiblemente una relación encubierta cuya esencia histórica ignoramos ${ }^{1}$.

El ensayo bajo discusión de Davide Tarizzo, "Después del euro: Soberanía nacional y hospitalidad europea", está escrito como propuesta directamente política, de hecho, como propuesta y empuje hacia un acto político fundacional o refundacional cuyo horizonte ostensible parecería ser todavía "la integración política del continente" (pág. 126), en momentos en los que la preocupación por la crisis de la llamada deuda soberana adquiere fuerzas centrífugas que podrían llevar a una cancelación del proyecto basado en la moneda única. Desde sus primeros párrafos la cuestión de la soberanía aparece problematizada en última instancia, pero el ensayo no lleva esa problematización hacia una tematización directa, sino que la suspende en nombre de un realismo comprensible.

Para Tarizzo hay soberanía del estado-nación pero sólo por el momento legitimidad europeísta, a pesar de que ciertos movimientos políticos recientes permiten poner sobre el tapete la soberanía subrepticia y antidemocrática, por lo tanto en último término ilegítima, de los que deciden sobre el uso de los dineros públicos en el ámbito continental. La demanda de invención política, dice Tarizzo, "no podrá librarse en el vacío sino que deberá partir de lo que hay, deberá salir al encuentro de lo existente trazando un punto de tangencia entre pasado y futuro para tornarlo, finalmente, un auténtico presente" (pág. 128). Tal realismo, sin embargo, acarrea siempre problemas que no pueden dejarse sin discusión. Mi propósito es presentar algunos de ellos, tomando pie en la cita del abate Siéyes que Tarizzo coloca en el marco de su argumento. Si para Siéyes no hay lista de cosas por hacer que no pueda ser fantasmalizada por una "lista teórica" que la determina, entonces se presenta la posibilidad de fantasmalizar el argumento mismo de Tarizzo. Mi idea es que su ensayo puede albergar una relación encubierta, que trataré de desocultar, entre su propuesta de una Europa de la hospitalidad y ese "recorrido de transición" hacia una soberanía inédita en el término de la integración política del continente que dice buscar.

En su ensayo de este mismo número, "L'invenzione del personaggio Europa", también dedicado al comentario de la idea de Tarizzo sobre la Europa de la hospitalidad, Rocco Ronchi insiste en que toda pretensión de invención política respecto de un espacio colectivo europeo, en la medida en que gire, positiva o negativamente, en torno al problema de la soberanía, debe considerarse dentro de la órbita "de la teología política", aunque sea dentro de un tipo de teología política "todavía en gran parte no sondeada". Su intento no es sólo condenar cierto pensamiento de la

\footnotetext{
${ }^{1}$ M. Heidegger, Holderlin’s Hymn "The Ister” (trad. del alemán de W. McNeill - J. David), Bloomington, Indiana UP, 1996, p. 49.
} 
impotencia, en Giorgio Agamben o Jean-Luc Nancy o Roberto Esposito, que estaría para Ronchi siempre en filiación directa con "el padre de todos estos teólogos de la soberanía imposible e inoperante", Georges Bataille. Para todos ellos "es siempre la persona la que constituye el modelo del soberano, ya sea que la persona sea el cuerpo místico del rey, que no muere nunca, o el cuerpo degradado y excesivo de quien no tiene lugar en este mundo y no cesa nunca de ser sacrificado". El intento de Ronchi es más bien, sobre todo, traer la propuesta de Tarizzo bajo la rúbrica de un intento de construcción democrática europeísta cuya proyección divina renuncia a la trascendencia identitaria y a todo sustancialismo analógico: un "deus transitus", le llama, que se agota en su acto mismo, un dios técnico o dios como técnica a cuyo cargo estaría la posibilidad misma de subjetivación histórica en un sentido propiamente democrático.

Para Ronchi parecería que no hay posibilidad de acto político, en el sentido fuerte que le da Tarizzo a esta expresión, que no esté de antemano apresado en la red teológica: todo acto político crea "un pueblo que no es", y en ese acto de creación, de producción creativa ex nihilo, alienta el dios del tránsito, cuya misión histórica sería la producción de una "soberanía inédita" o inaudita. Quizás por lo tanto la función intelectiva de ese dios no es otra que la que en otros tiempos pudo haberse llamado una filosofía de la historia ${ }^{2}$. Mi pregunta es si el deus transitus de la filosofía de la historia en el espléndido texto de Tarizzo, y a fortiori en el comentario de Ronchi, comparece todavía demasiado a favor, en sus márgenes, del viejo dios sustancialista, el dios de los pueblos y de los ejércitos. No debe leerse demasiado en estas líneas: mi apoyo y admiración por la postura de Tarizzo son sólidos. Pero, en el límite, Tarizzo parecería apostar -no es más que una sospecha- por una reasunción de la hegemonía política europea -europea y soberana- que a mí me gustaría llevar hacia postulados más resueltamente posthegemónicos e infrapolíticos, y quizás en esa medida ya no teológicos.

\footnotetext{
${ }^{2}$ Si la hay en Tarizzo, como creo a partir de la lectura hipotética que propongo más abajo, toma la forma no de una filosofía de la historia sino de un nuevo pensamiento de la historicidad que sigue la tradición heideggeriano-derrideana. A pesar de sus críticas a la "hipérbole espectral" derrideana (cf. D. Tarizzo, "L'esigenza dell'Europa, della filosofia, della democracia" [inédito]), creo que es legítimo proponer aquí, como marco de trabajo en el que se inscribe mi propio diálogo con Tarizzo, que ambos partimos de lo que Derrida ya precisó suficientemente: "Un conjunto de transformaciones de todo tipo ... excede tanto los supuestos tradicionales del discurso marxista como los del discurso liberal opuesto a ellos. Incluso si hemos heredado algunos recursos esenciales para proyectar su análisis, debemos primero reconocer que estas mutaciones perturban los esquemas ontoteológicos o las filosofías de la técnica en cuanto tales. Perturban las filosofías políticas y los conceptos vulgares de democracia, nos obligan a reconsiderar todas las relaciones entre estado y nación, hombre y ciudadano, lo privado y lo público, y todo lo demás... Este es el lugar en el que otro concepto de historicidad nos llama más allá del concepto metafísico de la historia y del final de la historia, ya derivado de Hegel o de Marx" (J. Derrida, Specters of Marx. The State of the Debt, the Work of Mourning \& the New International (trad. del francés de P. Kamuf), New York, Routledge, 1994, p. 70).
} 
En ese sentido, la gran política democrática europeísta, cuyo ejemplo sin ir más lejos es precisamente el texto de Tarizzo, tiene una piedra en el zapato. Olvida lo que a mi parecer constituye una objeción radical a toda propuesta de gran política: que, hoy, en el marco de la postdemocracia liberal que nos vive, se ha consumado ya y se consuma por doquier un paso inconspicuo (pero habrá otros) hacia el autoesclavizamiento personal que no será liquidado por ningún nuevo régimen de soberanía macropolítica ni por ninguna transición hacia él, porque es un paso transversal a la soberanía democrática o popular que sin embargo la subvierte en todos sus privilegios. No hay por qué no dar un ejemplo entre tantos que se podrían dar. Hace apenas unos días que, en mi lugar de trabajo, se trajo a examen un curioso documento preparado por un comité cuya misión es en principio la de asegurar la cordialidad corporativa y el respeto mutuo entre los trabajadores. El documento incluía una cláusula según la cual, si algún miembro del departamento fuera a tardar más de un día en contestar cualquier mensaje electrónico relacionado con la gestión administrativa en cualquiera de sus niveles, incluyendo el propiamente académico, ese miembro quedaría automáticamente sujeto a sanciones por la dirección -sanciones cuya severidad no venía especificada para cada caso, todas serían cuestión de estudio individualizado, pero podrían en última instancia incluir la terminación de contrato. Tal medida fue presentada y defendida como forma de asegurar colaboración y transparencia en la vida departamental, de garantizar eficiencia administrativa, y de buscar la reducción máxima del entorpecimiento que distintas prácticas profesionales potenciales de algunos podrían acarrear para otros. La medida quedó pospuesta para posterior voto sin objeciones obvias.

Nadie pareció notar que, bajo la coartada de la eficiencia administrativa, una vez que se produzca el voto anunciado, el cuerpo docente queda listo para sentencia cada vez que reciba un mensaje electrónico, al que a partir del momento mismo del voto habría ya que responder obligatoriamente en el plazo de ocho horas laborables. Lo extraordinario fue notar la buena disposición del personal al autoesclavizamiento supino, a la penalización sin límite, una vez fuimos informados de que tales medidas venían recomendadas por la administración superior y estaban siendo implementadas también en otros departamentos. Pensé si este asunto constituiría un ejemplo más de la poco notada pero ampliamente aceptada cesión de soberanía y autonomía personal que constituye para mí, junto con la creciente sobrecarga administrativa y el deterioro de toda noción de amistad profesional, el rasgo más notorio y destacado de la vida política en la universidad de los últimos treinta años. Sé, por experiencia personal, que este fenómeno no es exclusivamente norteamericano, sino asimismo europeo. La regla para todo trabajador de contestar el correo antes de ocho horas o exponerse a sufrir sanciones innombrables es quizá solo sinécdoque de cosas más terribles.

Vivimos nuestra vida diaria, nuestra vida laboral si es que tenemos la suerte de tenerla, o nuestra vida improductiva, si no la tenemos, en una especie de desasosiego 
acosado que se constituye como tal mediante prácticas de sometimiento a las que no cabe llamar propiamente políticas: son más bien biopolíticas, o infrapolíticas, en la medida en que permanecen por debajo de un vestíbulo de conciencia que no permite su denuncia como ostensiblemente anti-igualitarias o antidemocráticas ${ }^{3}$. Al contrario, mediante ellas se persigue una cierta igualación negativa, un sometimiento nivelizador y común a todos que es pasión de dominio, y pasión triste para la que resulta difícil encontrar un sujeto. Estas prácticas infrapolíticas de sometimiento, que prosperan hoy más que nunca en el ambiente laboral europeo y norteamericano, ciertamente en el académico, son lesión antisoberana en la medida en que destripan progresivamente cualquier pretensión de autonomía individual, de discreción productiva. Y llevan la entelequia misma de la hospitalidad a su desastre catastrófico. O más bien podríamos decir, si se me permite, que en ellas la pasión de hospitalidad revierte en pasión hospitalaria, entendiendo por esta última la voluntad de conversión del ciudadano, del trabajador, en mero vector o denominador común de salud pública. Cada uno tendrá sus propios ejemplos de todo esto, pero en todo caso yo ya he dado el mío. Conviene preguntarse si ese dios de la técnica de Ronchi, que él atribuye a la invención política de Tarizzo, no será también necesariamente el dios de la pasión hospitalaria: no es, claramente, el viejo dios de la soberanía popular-nacional, pero quizá se acerca ineluctablemente, claro que contra toda intención de Ronchi o Tarizzo, al último dios de la maquinación que Martin Heidegger contemplaba en sus pesadillas fascistas.

En lo que es ostensible que se trata de otro nivel discursivo Tarizzo pide la preparación de un acto político como gesto de invención, un "acto democrático de alcance europeo" (pág. 131), declarativo pero no, o todavía no, constituyente, que pueda consolidar una legitimidad europea no, o todavía no, soberana a favor de una "Europa de la hospitalidad" o "pueblo de extranjeros" (pág. 136). No se trata, para Tarizzo, de buscar primariamente consolidación de un inédito cuerpo colectivo, el europeo, el cuerpo soberano europeo, sino de buscar la consolidación previa de una colectividad espacial legitimada democráticamente. En la medida en que los únicos recursos de soberanía actualmente existentes son todavía las naciones que conforman el ente llamado Europa, el acto político imaginado convocaría a actuaciones nacionales y transnacionales no en nombre del ius soli o del ius sanguinis, sobre los que se basa ancestralmente la pertenencia a un cuerpo nacional, sino en nombre de un ius laboris cuya regulación sentaría las bases de esa Europa de la hospitalidad susceptible de entrar en un nuevo proceso de subjetivación histórica no identitaria. Y

\footnotetext{
${ }^{3}$ Tomo la expresión "desasosiego acosado" de Martin Heidegger: "Los mortales moran en que reciben el cielo en cuanto cielo. Dejan al sol y a la luna su periplo, a las estrellas sus cursos, a las estaciones su bendición y su inclemencia; no convierten la noche en el día ni el día en desasosiego acosado" (M. Heidegger, "Building Dwelling Thinking”, en Basic Writings (trad. del alemán de D. Farrell Krell), New York, Harper \& Row, 1977, pp. 319-339, aquí p. 328).
} 
todo esto vendría a quedar justificado mediante algunas consideraciones de carácter negativo y otras de carácter positivo, pero sobre el horizonte, este ya resueltamente constituyente, de un "recorrido de transición" hacia una futura, pero no próxima, Europa soberana (pág. 126). ¿Cuál sería su ventaja?

La consideración negativa es la premisa de que esta Europa de los huéspedes sería incompatible con la Europa del euro, y por lo tanto que el desmantelamiento de la unión monetaria es condición previa del acto declarativo. La razón que aduce Tarizzo es que no es el monopolio de la violencia ni el derecho a decidir sobre la excepción sino más bien la potestad de decisión sobre la gestión del dinero público la que es formadora de soberanía. Por lo tanto, en un ambiente de crisis que exacerba la toma de decisiones heteronómicas sobre cómo ciertos países de la Unión deben gestionar su dinero, o su deuda, la Europa del euro está promoviendo pulsiones de soberanía que no han sido refrendadas democráticamente y que chocan frontalmente con soberanías nacionales atávicas, lo cual puede acabar resultando en una regresión política paralizante, y antihospitalaria desde el punto de vista integrativo ("en ausencia de un «pueblo europeo», en ausencia de un nuevo pueblo soberano y supranacional del que por ahora no se entrevé siquiera la sombra en el horizonte, el proceso actual de integración política corre, en efecto, el riesgo de anular, volens nolens, el principio cardinal de la soberanía popular sobre el que se fundan todos los ordenamientos políticos modernos" [pág. 127]).

Las consideraciones positivas pertenecen a dos órdenes. Por un lado, el acto declarativo sería la sanción efectiva de lo que ya hay, en un estado avanzado de presencia, "la genuina invención de la Europa posbélica": "el efecto hospitalidad es el mayor efecto político del proceso de unificación económica del espacio europeo" (pág. 129). Por otro lado, la "Declaración de la dignidad del huésped europeo" sobre la base del ius laboris que propone Tarizzo tendría una fuerte ventaja política desde el punto de vista de la estrategia de integración democrática: "Una vez que la UE estuviera legitimada para fijar y tutelar a nivel comunitario los derechos de los trabajadores, estimulando así al mismo tiempo una progresiva uniformización del mercado laboral en el interior del continente, es presumible que las diversas formaciones sindicales distribuidas sobre el territorio nacional hicieran converger sus luchas en el interior de movimientos transnacionales o dentro de esquemas de alianza sindical que tenderían a sobrepasar los confines y los intereses de los respectivos países de pertenencia ... esto a su vez permitiría encender gradualmente la confrontación democrática, no sólo entre los partidos políticos nacionales, sino también entre partidos políticos europeos" (pág. 134).

La propuesta de Tarizzo es democratizante y europeísta, realista y gradualista, y permite construir sobre lo ya conseguido no solo histórica sino también prácticamente, de forma que se presenta tan intuitivamente factible como cualquier otra alternativa política. Uno podría preguntarse por qué es tan importante marcar la incompatibilidad de esta Declaración de una Europa de la hospitalidad con la continui- 
dad de la Europa del euro. Puede concebirse, quizás con mayor efectividad política, un escenario en el que la Europa del euro marche adelante de forma tan renqueante como en los últimos años a favor de un mejoramiento relativo en las condiciones macroeconómicas y a la vez se plantee un movimiento político a favor de la serie de medidas que podrían garantizar una infraestructura legal y una voluntad unitaria para la legitimización de esa Europa de la hospitalidad de Tarizzo, entendida propositivamente como deus transitus hacia la subjetivación soberana. A no ser que entre en nosotros la sospecha de que lo que verdaderamente pide Tarizzo (y entonces su curiosa insistencia en que no puede haber Europa de la hospitalidad si hay Europa del euro puede entenderse como un síntoma, un nudo sintomal), a través de un "icuán largo me lo fiáis!" que pertenece también al corazón teológico-político de la cultura europea desde su sur católico, es la configuración de una Europa de la hospitalidad sin voluntad alguna de autoconstitución soberana, es decir, sin tránsito hacia la plena soberanía inédita del "pueblo que no es," convocado sólo como espectro útil pero en última instancia enemigo.

El deus transitus de Tarizzo sería más bien, en ese caso, el dios de una transición infinita, transición sin tránsito, cuya convocación productiva no sería por lo tanto específicamente teológica: se trataría más bien de una treta de la razón antiteológica. Pero esta hipótesis, que yo favorezco como hipótesis de lectura, debe permanecer no más como sospecha, pues no registra lo que el texto dice explícitamente, aunque el demonio lo piense. Al fin, un pueblo de extranjeros no podrá nunca revenir en cuerpo colectivo, ni querría hacerlo. Un pueblo de extranjeros, de extrañados, de viajeros, un pueblo para quien el último recurso de habitación sería una formación de jurisprudencia, y ya no al revés, un pueblo en el que ciudadanos comunitarios y extracomunitarios quedaran vinculados por su extrañamiento mismo, a través de una hospitalidad decretada por la autoridad legal, no aspiraría a convertirse en pueblo soberano no sólo porque los viejos criterios de la sangre o el suelo se habrían hecho tan abstractos que ya apenas podrían invocarse de forma genealógica: también porque esa soberanía inédita habría perdido toda conexión orgánica con el desnudo habitamiento que precede y organiza la distribución espacio-temporal de lo humano y funda la posibilidad misma de la política. La invención política corre aquí el riesgo de meterse en la boca más de lo que puede masticar: a través de la previa radical extranjerización de la ciudadanía, que es la otra cara de la hospitalidad, y quizá el referente fundamental de la idea de Tarizzo de que ninguna invención política puede prescindir de lo que ya hay como realidad fáctica. Quizá la hospitalidad europea pueda reentenderse, trágica o cómicamente, como hospitalismo europeo. El huésped tarda tres días en hacerse siniestro cuando mora en la casa de otro huésped. La estructura de la hospitalidad solo puede sostenerse en su precariedad misma cuando hay posesores de la tierra.

Quizás sea la misma sospecha, su mismo tipo, el que lleve también a cuestionar esa posibilidad bienvenida por Tarizzo de una macrorregulación europea del derecho 
del trabajo. Por un lado, hemos de suponer por lo pronto que ninguna regulación transnacional y unitaria del derecho del trabajo va a renunciar a los valores mismos en los que se asienta el mantra infrapolítico neoliberal, él mismo consecuencia de cierta racionalización capitalista de larga historia: productividad, transparencia, colaboración, desubjetivación, igualización. La macrorregulación del derecho del trabajo podría muy bien convertirse en el deus transitus por excelencia hacia la máquina hospitalaria, hacia la maquinación misma del extranjero, es decir, de todo europeo ya convertido por definición en extranjero en esa Europa de la hospitalidad siniestrada en lo hospitalario. Por otro lado, el énfasis de Tarizzo sobre la posibilidad de un "encenderse" de la confrontación democrática que sería el resultado de una continentalización de la vida del trabajo puede apuntar al nacimiento de luchas antihegemónicas cuyo contenido mismo, en el ámbito de un continentalismo no sostenido en la soberanía sino en la legitimidad, no buscaría la formación de una hegemonía alternativa, sino que sería resueltamente disolutorio de la posibilidad hegemónica misma: esa es la promesa de la sindicalización masiva de los extranjeros, que yo entiendo como el rasgo más extraordinariamente utópico, y en esa medida venturosamente político, de la propuesta de Tarizzo. Pero esta es una invención sin invento, posthegemónica, infrapolítica.

Para el viejo Heidegger, el Heidegger de la inmediata posguerra que sustituyó la noción de patria alemana por la de intemperie o Heimatlosigkeit, era esa intemperización de la vida la que iniciaba el proceso de desasosiego acosado como disposición básica del europeo contemporáneo. Esta es la dimensión infrapolítica que no está explícitamente notada en el texto de Tarizzo - de su texto se podría casi decir lo que dice Heidegger del problema fundamental de habitar nuestra época, que es no pensar en el problema fundamental del habitar en nuestra época, si no fuera porque se puede justamente decir lo contrario. Su mención continua y estructurante del extranjero, del que tiene derecho a la hospitalidad, de una Europa configurada en el habitar hospitalario, me da licencia para arriesgar la hipótesis de que hay un subtexto en el texto de Tarizzo que está lejos de agotarse en su declaración misma. Ese subtexto apunta a una consideración del espacio europeo ya no regido por la conveniencia geopolítica de una nueva formación de soberanía hegemónica.

En el seminario de 1942, no cualquier año para los alemanes, sobre el Himno "El Ister", de Friedrich Hölderlin, dice Heidegger la frase que coloqué como epígrafe a este comentario: "Entre el alcance espacio-temporal que se mueve hacia la dominación planetaria y el movimiento de asiento que es funcional a tal dominación por un lado, y el deseo de los humanos de habitar en su sitio en el viaje y la localidad, por otro, prevalece posiblemente una relación encubierta cuya esencia histórica ignoramos"4. Hay una voluntad política y metafísica, teológico-política si se quiere, de dominación planetaria a la que Europa no ha sido ni es ajena. Hay un proceso de

${ }^{4}$ M. Heidegger, Holderlin's Hymn "The Ister", op. cit., p. 49. 
asentamiento poblacional que cambia según las épocas y que es funcional al régimen de dominación. Heidegger postula, como es notorio, una recuperación de la esencia del habitar propiamente humano a través de un retorno o comienzo otro cuya posibilidad misma radicaría en la dilucidación de esa "relación encubierta". A mi juicio es esta misma relación encubierta la que domina, en cuanto denegada, pero en profundidad el texto de Tarizzo, cruzado de una tropología que enfatiza el desplazamiento, la extranjerización, el habitar democrático, lo hospitalario, el pueblo que no es ni ha llegado a ser. El alcance espacio-temporal de la dominación es la contrapartida del desasosiego acosado que está en el envés del texto de Tarizzo, igual que el deseo de habitamiento hospitalario coincide en Tarizzo con una constitución democrática del espacio europeo. El énfasis que pone Heidegger en el viaje o el viajar, en estar en camino, que para Heidegger queda vinculado a la esencia del río en el poema de Hölderlin, puesto que el río es en el poema imagen "del viajar de los humanos en cuanto históricos hacia su habitar en la tierra", hace del habitar no solo una estructuración del espacio sino tambien algo radicalmente histórico, como ese "recorrido de transición” (quizá) sin tránsito de Tarizzo. Tambien para Heidegger la intemperización de la vida contemporánea, al revelar que por lo pronto significa el no habitar en casa, el ser o habernos convertido en (no)sujetos de habitación, implica históricamente lo que él llama "el paso por lo extranjero": "La ley del encuentro [Auseinandersetzung] entre lo extranjero y lo propio es la verdad fundamental de la historia, la verdad desde la que debe desvelarse la esencia de la historia".

¿Hay pues una filosofía de la historia en el texto de Tarizzo? Si el fin de su tránsito fuera la constitución última de la soberanía inédita del pueblo que no es, entonces la propuesta de Tarizzo estaría todavía implicada en ese movimiento hacia la dominación o codominación planetaria, y el asentamiento hospitalario que propone sería un aspecto de su estrategia y funcional a él: la hospitalidad sería solo un tránsito hacia el principio soberano. Pero las vidas deshabitantes o deshabitadas, en desasosiego acosado, de las que la hospitalidad habla y a las que la hospitalidad reacciona, pueden ser necesarias, ordenadas por una historia cuya esencia permanece oculta. Desocultarla es lo que debe buscar el pensamiento. Es típico del Heidegger de esos años del final de la segunda guerra mundial insistir en que todas nuestras representaciones espacio-temporales, toda nuestra imaginación geográfica estaba marcada por una metafísica no solamente cristiana, no ya solamente cristiana, sino triunfante como maquinación y en la maquinación técnica. La respuesta no habría sido huir de la técnica, sino abrazarla como deus transitus hacia una habitación que no es, que todavía no es, y que yo debo traducir al "pueblo que no es" tarizziano, en sí posible sujeto inconcluso de una inédita soberanía no identitaria, no analógica. Para Tarizzo, por lo tanto, la historia parecería jugarse en el tránsito entre soberanías, desde un

\footnotetext{
${ }^{5}$ Ibidem, p. 33.

${ }^{6}$ Ibidem, p. 49.
} 
pueblo que eso fue hacia un nuevo pueblo que no es, excepto por la sospecha de que en el límite la presencia constituyente del nuevo pueblo se desvanecerá en el tiempo, excepto por la sospecha de que, para Tarizzo, su deus transitus no abre tránsito alguno y es concebido mayormente como funcionalización de una posible conflagración democrática. El Auseinandersetzung heideggeriano entre lo extranjero y lo propio queda en Tarizzo marcado, aunque fantasmalmente, como deconstrucción categorial en la categoría misma de hospitalidad incendiable o bien hospitalidad invertida en hospitalismo. Si en el Heidegger de 1942 no podemos evitar pensar que su llamada al encuentro y confrontación entre lo extranjero y lo propio podía servir como justificación siniestra de la guerra, Tarizzo propone un incendio o una luz concebida como conflagración democrática entre sindicatos del trabajo y marco legal y político de una Europa autoconcebida según leyes de hospitalidad. La verdadera invención política de su texto no consiste sino en ese aliento utópico o mesiánico que puede alumbrar el resultado de tal conflagración.

Algunos años más tarde, en "La cuestión de la técnica", escrito en 1949 y revisado en 1953, Heidegger usó las palabras Ge-Stell y Bestand, que tienden a traducirse parcialmente como "posicionalidad" y "reserva disponible". Ambas palabras constituyen una nueva clarificación de la pérdida de morada o habitación europeas. La pregunta sobre la técnica no es entonces fijable en una pregunta sobre la técnica sino que aparece primariamente como pregunta sobre la deshabitación de nuestra época, ahora quizá decible como dis-posición, a partir de la cual la posicionalidad de nuestras vidas quedará siempre estructuralmente dislocada hacia el desasosiego acosado de la triste pasión hospitalaria. En la pasión hospitalaria el mundo se hace reserva disponible, igual que el huésped europeo, o particularmente el huésped europeo, es siempre de antemano aquello a lo que se le ordena "que esté ahí, que esté inmediatamente a la mano, que no deje de estar ahí para que pueda ser dis-puesto para una nueva orden. Lo que queda así ordenado tiene su propia disponibilidad. Es la reserva disponible"7. Pero Tarizzo no llama ya a este ejército servil el ejército de los inmigrantes, mano de obra disponible, sino que su Europa de la hospitalidad es también y primariamente la Europa de los europeos, la Europa ciudadana, puesto que todos somos ya sujetos de hospitalidad y no otra cosa, y por lo tanto no más que (no)sujetos hospitalarios, sujetos de cálculo y calculabilidad, susceptibles de ser integrados legítimamente o no, pero siempre ordenables estadísticamente, sujetos de información y sujetos de sistema poblacional.

Hay siempre otro paso en el autoesclavizamiento y la infinita penalización de nuestra vida, más allá del desasosiego acosado. En su ensayo del 49/53 Heidegger se refiere a ello hablando de una "caída precipitada" en el espacio en el que el humano

\footnotetext{
${ }^{7}$ M. Heidegger, "The Question Concerning Technology", en The Question Concerning Technology and Other Essays (trad. del alemán de W. Lovitt), New York, Harper \& Row, 1977, pp. 3-35, aquí p. 17.
} 
deja de considerar al otro reserva disponible para convertirse a sí mismo en tal ${ }^{8}$ : ese es el momento de dis-locación hospitalaria en el que ninguna sanción autoimpuesta es ya perceptible como tal, en el que se naturaliza el esfuerzo mismo de acoso como autoacoso terminal: cuando el huésped ya no tiene anfitrión, pues el anfitrión ha usurpado la extranjerización del huésped. La ilocación aparece ahora como vida biopolítica en la que la distancia mínima susceptible de permitir una brecha entre el odio a la opresión y la experiencia de opresión se ha desvanecido. Ya no hay un afuera, apenas un campo general de identidad tenue que trasciende, deus transitus, el desasosiego acosado hacia un improbable acoso desasosegado que es la fijeza biopolítica misma, su infinitización. Contra Ronchi habría que decir que Agamben, Nancy o Esposito, sin duda el mismo Bataille, cualesquiera sus limitaciones, piensan esta intuición como relación encubierta en todo pensamiento ostensiblemente político.

${ }^{8}$ Ibidem, p. 27. 